\title{
A Kind of Wave Passive Compensation Device's Rope Tension Research
}

$$
\text { Zhiqiang } \mathrm{Xu}^{1.2 \text {. a }} \text {, Xiangyong } \mathrm{Liu}^{3 . \mathrm{b}^{*}} \text { and Zhixin Shen }{ }^{1.2}
$$

${ }^{1}$ Key Laboratory of Fishery Equipment and Engineering, Ministry of Agriculture, Shanghai 200092, China

\section{${ }^{2}$ Fishery Machinery and Instrument Research Institute, Chinese Academy of Fishery Sciences, Shanghai 20092, China}

${ }^{3}$ School of Machinery and Energy Engineering, Tongji University, Shanghai 201804, China

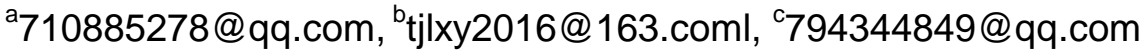

${ }^{*}$ The corresponding author

Keywords: Wave compensation; Rope tension; Mathematical model; Experimental evidence

\begin{abstract}
In the large water trawler system work process, trawlers are influenced by the marine environment, can produce large movement, which seriously affect the drag efficiency. This study is based on a wave passive compensation device, establish its mathematical model for the simulation analysis, design the test process, extract and analyze the test data. Finally compared with the theoretical analysis results and found that: Wire rope tension change in cycle according to displacement's cycle (caused by external disturbances), displacement has different trend with the rope tension. When the displacement amplitude is in less than $50 \mathrm{~mm}$, rope tension keep stable; Suffered the effect of inertia force, the speeds of tension change in different stages. By the simulation analysis, the larger the gas pressure of accumulator in the equilibrium position, the greater the tension; The larger the accumulator's area, the smaller the tension.
\end{abstract}

\section{Introduction}

Trawlers are an important platform for the Marine salvage, and after the target floats into the net, the boat's winch tightening equipment will frap the net. Wave fluctuation causes the net insert into the water difficultly, because the net width in water is fluctuant, which influence the salvage success rate. So we designed a wave compensation device, in order to reduce the influence of the fluctuation, as shown in Fig. 1. Home and abroad research mainly concentrate on how to control the ships gesture to reduce the wave influence, there are also institutions controlling the ship's side boom angle to reduce the influence of the waves, but no research on the designed device [1].

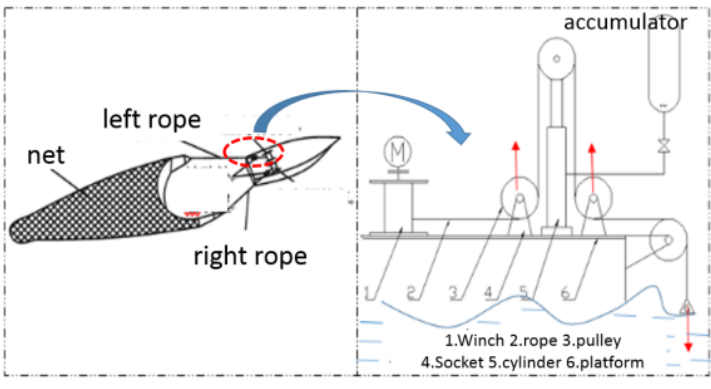

Figure 1. Trawler system

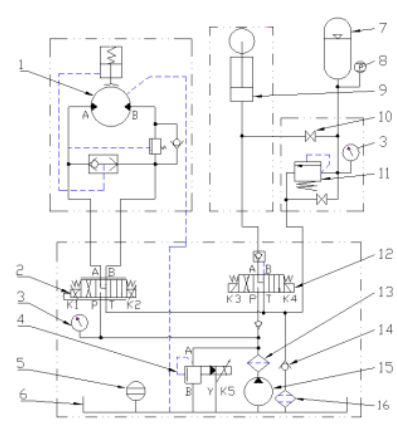

Figure 2. Hydraulic principle diagram of Trawler

\section{The Wave'S Passive Compensation Device and Its Mathematical Model}

Passive compensation device is also called constant tension compensation, when the platform rises, the cylinder will raise together, the piston rod connected to oil cylinder stays in the initial position under the effect of inertia, oil is pressed into accumulator from rod less cavity and stored energy. 
Through accumulator's energy storage and release process to slow down the process of rope tension, and ensure the wire rope is always at a constant value within certain scope. The following Fig. 2 is the hydraulic principle diagram of trawler [2].

Set $(P 1, V 1)$ as initial gas pressure and volume, $(P 2, V 2)$ is another state, the accumulator's gas adiabatic equation is:

$$
\begin{aligned}
& P 2 . v 2^{n}=P 1 . v 1^{n} \\
& \ln p 1+n . \ln v 1=\ln p 2+n . \ln v 2
\end{aligned}
$$

Draw the value of $n$ value in gas adiabatic equation, shown in Fig. 3 below. The value of $n$ is time-varying, range from 1.1 to 1.5 , and takes the average result: $\mathrm{n}=1.35$.

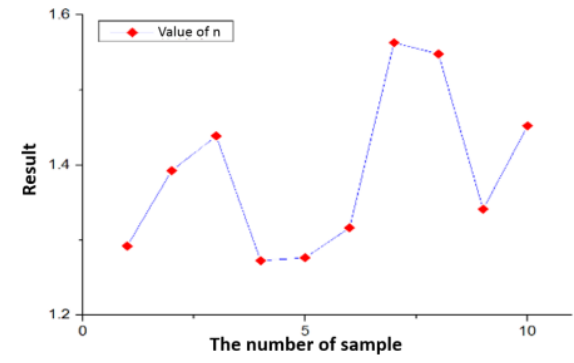

Figure 3. Gas state equation's n value

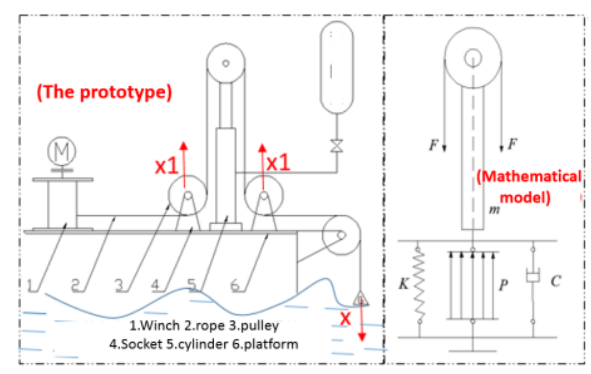

Figure 4. Piston rod's simplified mechanical model

$\mathrm{N}$ values in gas state equation is greatly influenced by the outside conditions[3], through the experiment, testing 10 groups of data, including accumulator pressure and cylinder displacement , then insert the group $i$ and group $i+1$ into equation (3) to get $n$ value, as shown in Table 1.

Table 1 Accumulator's sample values

\begin{tabular}{|l|l|l|l|l|l|l|l|l|l|c|}
\hline Number: $\mathrm{i}$ & 1 & \multicolumn{1}{|c|}{2} & \multicolumn{1}{c|}{3} & 4 & 5 & 6 & 7 & 8 & 9 & 10 \\
\hline Displace: $\mathrm{h}$ & 254.05 & 217.2 & 289.438 & 230.313 & 277.06 & 175.61 & 186.571 & 203.168 & 167.78 & 196.93 \\
\hline Pressure: $\mathrm{p}$ & 43.656 & 48.560 & 39.085 & 46.842 & 42.473 & 45.294 & 46.983 & 48.288 & 42.079 & 46.457 \\
\hline Result: $\mathrm{n}$ & 1.192 & 1.2924 & 1.3387 & 1.1727 & 1.1765 & 1.2164 & 1.4731 & 1.4481 & 1.2411 & 1.3521 \\
\hline
\end{tabular}

Write dynamic equation [6-11]:

$$
\begin{aligned}
& m \ddot{x}_{1}+c \dot{\mathrm{x}}_{1}+k x_{1}=2 F-P_{2} A \\
& p_{2}=p_{1}\left(\frac{v_{1}}{v_{1}+0.5 * A}\right)^{1.38}
\end{aligned}
$$

P1 is accumulator's pressure in balance position, insert (5) into (4) to get the relationship between the displacement and rope tension:

$$
F=\frac{m}{4} \ddot{x}+\frac{\mathrm{c}}{4} \dot{x}+\frac{p_{1} A}{2}\left(\frac{v_{1}}{v_{1}+0.5 A}\right)^{1.38}
$$

Set platform's quality $\mathrm{m}$, damping coefficient $\mathrm{c}$, displacement $\mathrm{h}$ and area A which are constant. Then set equilibrium position's pressure as $252 \mathrm{Kg} 、 378 \mathrm{Kg} 、 540 \mathrm{Kg} 、 630 \mathrm{Kg} 、 756 \mathrm{Kg}$,simulation results are shown in Fig. 7. Results show that with the increase of pressure, the tension and its amplitude increase. So in order to keep tension stable, it's necessary to keep pressure less than certain value. 


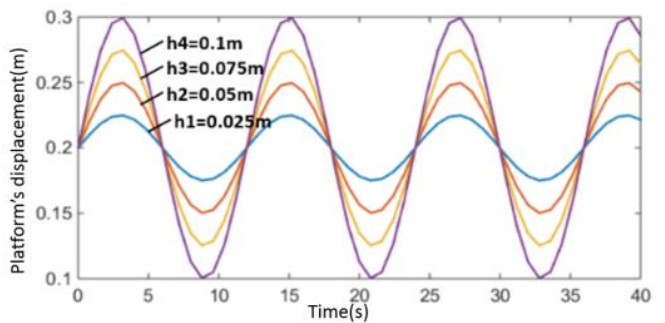

Figure 5. Hoist's displacement fluctuation

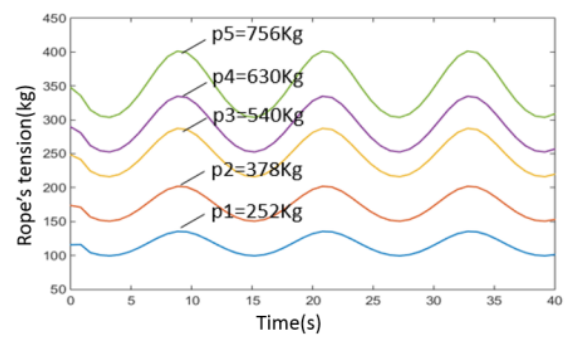

Figure 7. Wire rope's pulling force change

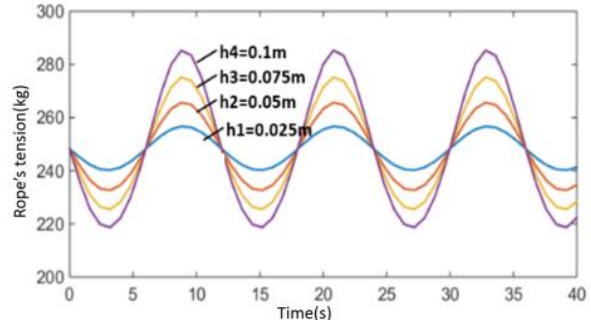

Figure 6. Wire rope's pulling force change

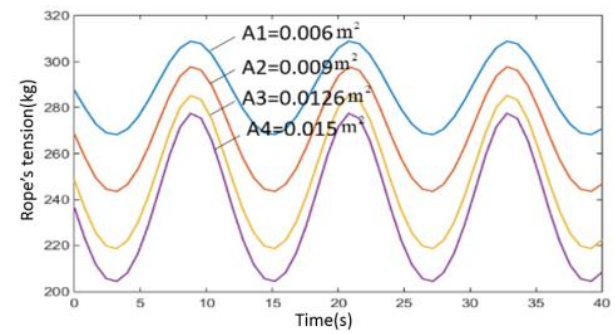

Figure 8. Wire rope's pulling force change

Set platform's quality $\mathrm{m}$, damping coefficient $\mathrm{c}$, displacement $\mathrm{h}$ and equilibrium position's pressure constant. Then set area as $0.006 \mathrm{~m}^{2} 、 0.009 \mathrm{~m}^{2} 、 0.0126 \mathrm{~m}^{2} 、 0.015 \mathrm{~m}^{2}$,simulation results are shown in Fig. 8. Results show that with the increase of area, the tension decrease and its amplitude increase.

\section{Experiment Research}

Experiment location is on a wave platform, the simulation platform can generate sine vibration with the trends: front and back, left and right, up and down. The wave simulation experiment platform is shown in Fig. 9.
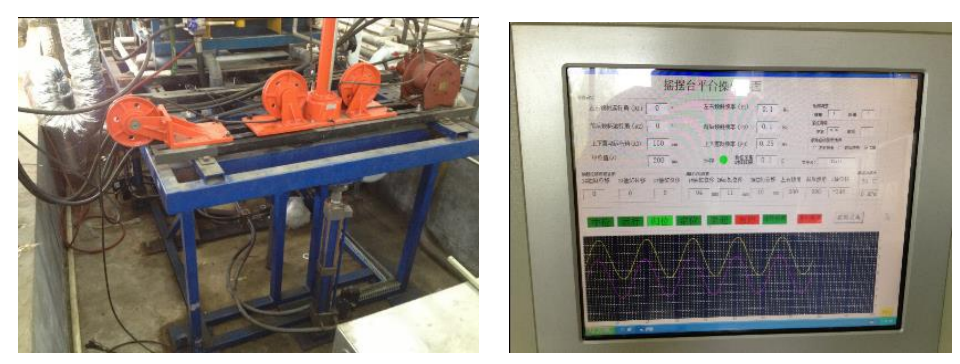

Figure 9. experiment platform Figure 10. PC control platform

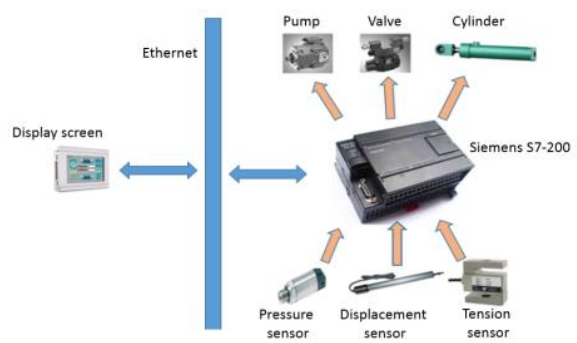

Figure 11. hardware connection

This test platform is equipped with TTC Company's HY series screen, to monitor the parameters of the wave compensation system, and through the screen to enter the hydraulic system's control parameters. The PC interface of wave compensation system is shown in Fig. 10.This system chooses Huba Control company's 511 type pressure tension, and displacement sensors, which were used to collect the pressure of the accumulator, wire rope tension and the displacement.

Experiment process is divided into five stages, by controlling the amplitude of displacement, frequency, basic value, study the characteristics of the tension of the steel wire rope under different conditions.

(1) Stage NO (T1): 0 seconds - 120 seconds

In this phase, control platform's displacement amplitude is within $50 \mathrm{~mm}$, result show that wire rope tension keeps stable at about $270 \mathrm{~kg}$, wire rope's tension fluctuation is small. According to the simulation waveform shown in Fig. 6, the larger the displacement fluctuation, the larger the tension fluctuation, get the conclusion that: when the displacement range is less than $50 \mathrm{~mm}$, tension will be stable in a certain value. 


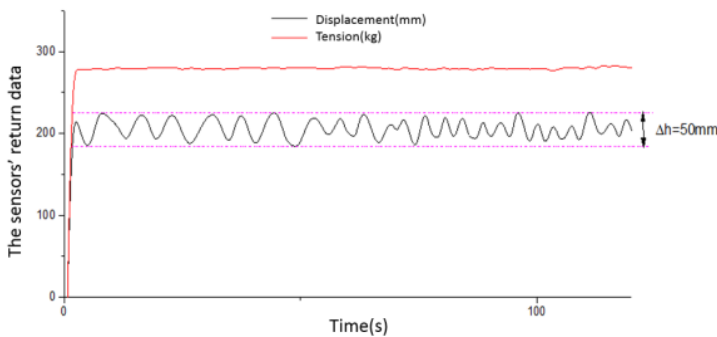

Figure 12. value in the first stage

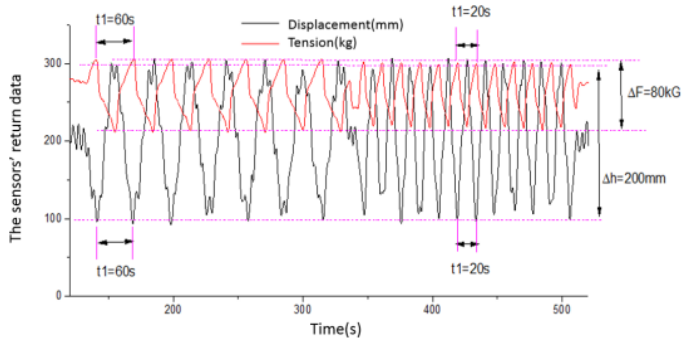

Figure 13. value in the second stage

(2) Stage NO (T2) : 120 seconds - 520 seconds

In this phase shown in Fig. 13, to control displacement range within $200 \mathrm{~mm}$; in the $120 \mathrm{~s}-350 \mathrm{~s}$ stage, cycle period is $60 \mathrm{~s}$, in the $350 \mathrm{~s}-520 \mathrm{~s}$ stage, cycle period is $20 \mathrm{~s}$, results show that tension amplitude is $80 \mathrm{~kg}$, change around $260 \mathrm{~kg}$.

(3) Stage NO (T3) : 520 seconds - 920 seconds

In this stage shown in Fig. 14, set the displacement amplitude $120 \mathrm{~mm}$. In the $520 \mathrm{~s}-750 \mathrm{~s}$, displacement's cycle period is $50 \mathrm{~s}$. In the $750 \mathrm{~s}-920 \mathrm{~s}$, displacement's cycle period is $15 \mathrm{~s}$.

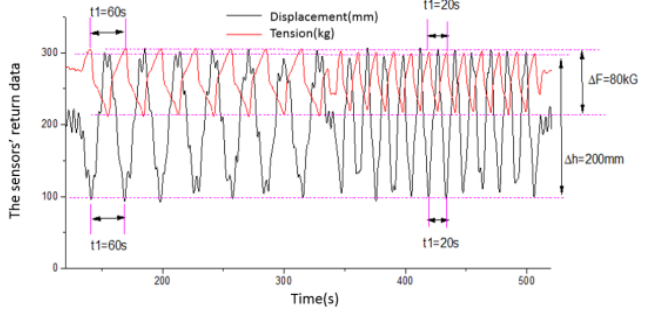

Figure 14. value in the third stage amplitude

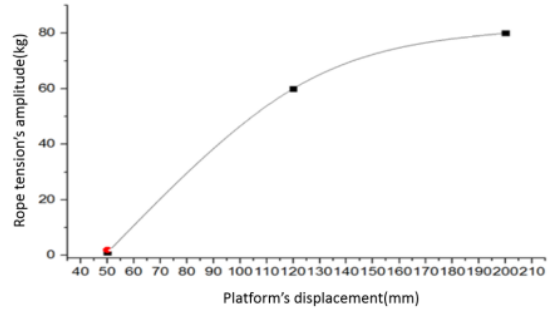

Figure 15. The trend of sensors' feedback value

Combining with Fig. 6, Fig. 7 and Fig. 8, set displacement as $\mathrm{X}$ coordinate and tension as $\mathrm{Y}$ coordinate; the change trend is drawn in Fig. 15. Conclusion: with the increase of the displacement, wire rope's tension amplitude increase.

(4) Stage NO (T4) : 920 seconds - 1400 seconds

As shown in Fig. 15, set the displacement amplitude within $100 \mathrm{~mm}$. In the $920 \mathrm{~s}-1170 \mathrm{~s}$, displacement change in cycle with $30 \mathrm{~s}$ period, and $1170 \mathrm{~s}-1400 \mathrm{~s}$, with $15 \mathrm{~s}$ period.
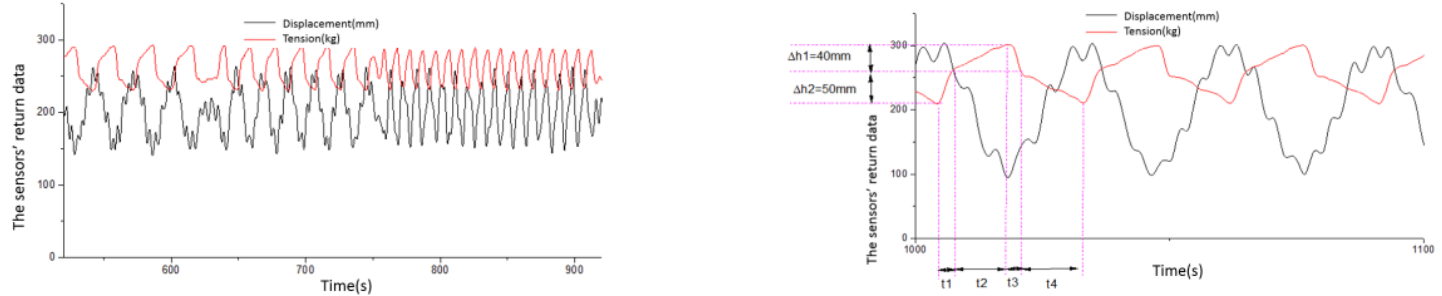

Figure 16. Sensors' feedback value in the fourth stage Figure 17. Sensors' feedback value in part time

In the fourth stage, pick the $1000 \mathrm{~s}-1100 \mathrm{~s}$ data shown in Fig. 17. There are four stages in one cycle, and they are $\mathrm{t} 1=4 \mathrm{~s}, \mathrm{t} 2=11 \mathrm{~s}, \mathrm{t} 3=3 \mathrm{~s}, \mathrm{t} 4=12 \mathrm{~s}$.

(5)Stage NO (T4) : 1400 seconds - 1500 seconds

As shown in Fig. 18, set the wire rope's tension amplitude is $50 \mathrm{~mm}$, change around $305 \mathrm{~mm}$. When amplitude is same, the larger the displacement, the smaller the wire rope tension is. 


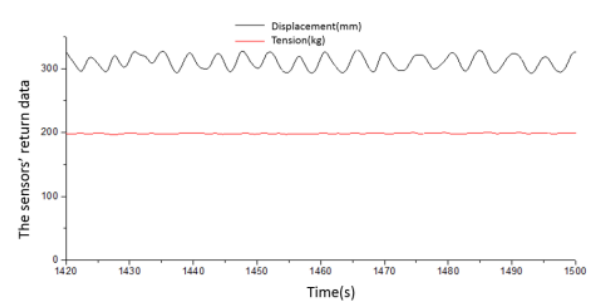

Figure 18. Sensors' feedback value in the fifth stage

\section{Conclusions}

By designing hydraulic system, selecting sensors with high precision, designing electronic control system's hardware and software, made one wave passive compensation platform. Establish the platform's mathematic model, and analyze the model with Simulink simulation, adopting rational method to analyze the experimental data, its results is consistent with the theoretical analysis, and finally get some features of the wave passive compensation system.

(1)The wire rope tension change in cycle with the same period of displacement, the tension and displacement change in contrary trend.

(2)With the increase of the displacement, wire rope's tension amplitude increase. To maintain the stability of tension, the platform's displacement should be set less than $50 \mathrm{~mm}$.

(3)The wire rope tension cycle is divided into four stages, due to the effect of inertia force, different stage have different changing speed.

(4)By simulation analysis, wire rope tension is related to accumulator's equilibrium position pressure and area. The larger the equilibrium position's pressure, the larger the tension. The larger the area of the accumulator, the lower the tension is.

\section{Acknowledgements}

Agriculture ministry's science and technology research project: "the Antarctic krill trawl drag steel tension balance's control technology research" (201203018); Guangdong Marine economic innovation development demonstration area's special project (GD2013 - D01-001)

\section{References}

[1] Ren Keren, Shen Da-chun, Wang Ding-ya, et al. Analysis of ocean drilling heave compensation system [J]. China Petroleum Machinery, 2009, 37(9):125-128.

[2] Li Wan-li. Design of hydraulic system of construction machinery [M]. Shanghai: TongJi University Press, 2011.

[3] Zhang Ying-chun, Ning Yan-ping, Lu Yuan-san. Application of large capacity piston accumulator [J].Chinese Hydraulics \& Pneumatics, 2013 (1):86-88.

[4] Y.G. Sun, H.Y. Qiang, D.F. CHANG, R. WANG. Response Characteristic Analysis of Nonlinear Vortex-Induced Vibration of Tension Leg Platform in Deep Sea [J]. Journal of the balkan tribological association, Vol.22 (2016) No.3, p.2519.

[5] Y. G. Sun, W.L. Li, D. S. Dong, X. Mei and H. Y. Qiang, Dynamics Analysis and Active Control of a Floating Crane [J], Tehnicki Vjesnik-Technical Gazette, Vol. 22 (2015) No.6, p.1383Zheng

[6] Zhang Yan-ting, Li Zhen-dong, Jiang Hao, et al. Study on active force of compensation system for floating drilling platform [J]. Oil Field Equipment, 2010, 39(4):1-4.

[7] Liu He, Li Bin, HU Xiao-dong. The study of heave compensation boat-lifting winch [J].Shanghai Shipbuilding, 2008 (2) : 30-31. 
[8] TAKAGAWA S.A new concept design of heave compensation system for longer life of cables [D].Tokyo: The University of Tokyo, 2015.

[9] Liu J, Hou Z, Chen X, et al. Experimental and numerical study on the aero-heating characteristics of blunted waverider. Applied Thermal Engineering, 2013, 51(1): 301-314

[10]Cui K, Li GL, Xiao Y. Aerodynamic performance study of high pressure capturing wing configuration. AIAA Paper 2015-3388, 2015.

[11]Lobbia M, Suzuki K. Multidisciplinary Design Optimization of Hypersonic Transport Configurations Using Waveriders. AIAA Paper 2014-2359, 2014.

[12] Y.G. Sun, H.Y. Qiang, X.M. Sheng. Genetic Algorithm-based parameters optimization for the PID Controller applied in Heave Compensation System [C]. International Conference on Mechatronics Engineering and Computing Technology (Shanghai, CHINA, APR 09-10, 2014). Vol. 556-562, p. 2462.

[13] Y.G. Sun, H.Y. Qiang, G.B. Lin, J.D. Ren, W.L. Li. Dynamic Modeling and Control of Nonlinear Electromagnetic Suspension Systems[C]. International Conference on Applied Engineering and Management (Beijing, PEOPLES R CHINA, SEP 11-14, 2015). Vol. 46, p. 1039. 